\title{
The Experience of Transitioning from Being a New York City Paramedic to Medical Intern in the Dominican Republic
}

\author{
Reynolds A. Kairus.
}

\begin{abstract}
The Experience
When breaking down the word paramedic - para is a prefix for beside and medic stands for a doctor or medical practitioner (Available from: http://www.wordcentral.com/cgi-bin/student?paramedic, updated 2007; cited 2018 Feb 13.). We are an extension of the doctor in people's homes and in the prehospital setting. Working as an emergency medical service (EMS) provider in New York City (NYC) before medical school as well as during medical school in Dominican Republic (DR) gave me great insight on medical practice.
\end{abstract}

In NYC the emergency rooms (ERs) filled over capacity go into diversion, while in DR ERs this is not an option (Figure 1). In the DR, medical students, residents, and sometimes even patient's relatives serve the role as respiratory therapist, squeezing the oxygen bag for an intubated patient for days on end due to the constant shortage of ventilators.

Being an experienced paramedic allowed me to make invaluable correlation from patients seen in the pre-hospital setting with lectures and clinical exposures during medical school. I have seen the manner in which the evolution of medical mnemonics like $A B C$ (Airway, Breathing, Circulation), later replaced with $C A B$ (compressions, Airway, Breathing), likewise MONA (Morphine, Oxygen, Nitroglycerin, Aspirin) and LMNOP (Lasix/Loop diuretic, Morphine, Nitroglycerin, Oxygen, Position: Prop up the patient) save the lives of many. Other invaluable lessons were learning how to cope with stress, recognize life threating conditions and use the skills learned to act accordingly.

I became an emergency medical technician in 2003 and then a paramedic in 2007 and my scope of practice went from basic life support to advanced life support, respectively. ${ }^{2}$ I started pre-med in 2010 and medical school in 2013 in the DR. I completed my training (internship) in the DR public health system (PHS). The internship was pretty eventful, to say the least. We had remodeling, Pseudomonas contamination of the water supply, hospital staff being robbed and/or kidnapped near hospital grounds and a multi-drug resistant Tuberculosis scare.

Despite these calamitous circumstances the medical training in the DR has been extremely beneficial. Interns in this PHS who show interest, are team players and are willing to ask for an opportunity can obtain hands on experience which other medical students in more developed countries can only dream of. For example, I've been able to scrub into and assist in a variety of surgeries, I've intubated pediatric and adult patients and been able to teach CPR and First Aid to lay rescuers and health care providers, just to name a few.
As a paramedic, I immediately noticed improvements that can be made on the ambulances. Usually the ambulances are under-equipped and staffed with people who did not receive formal basic life support (BLS)

or advanced cardiac life support (ACLS) training. In the vast majority of cases the patients are transported by their families, which more often is the quicker option.

Figure 1. Lower Extremity Fraction.

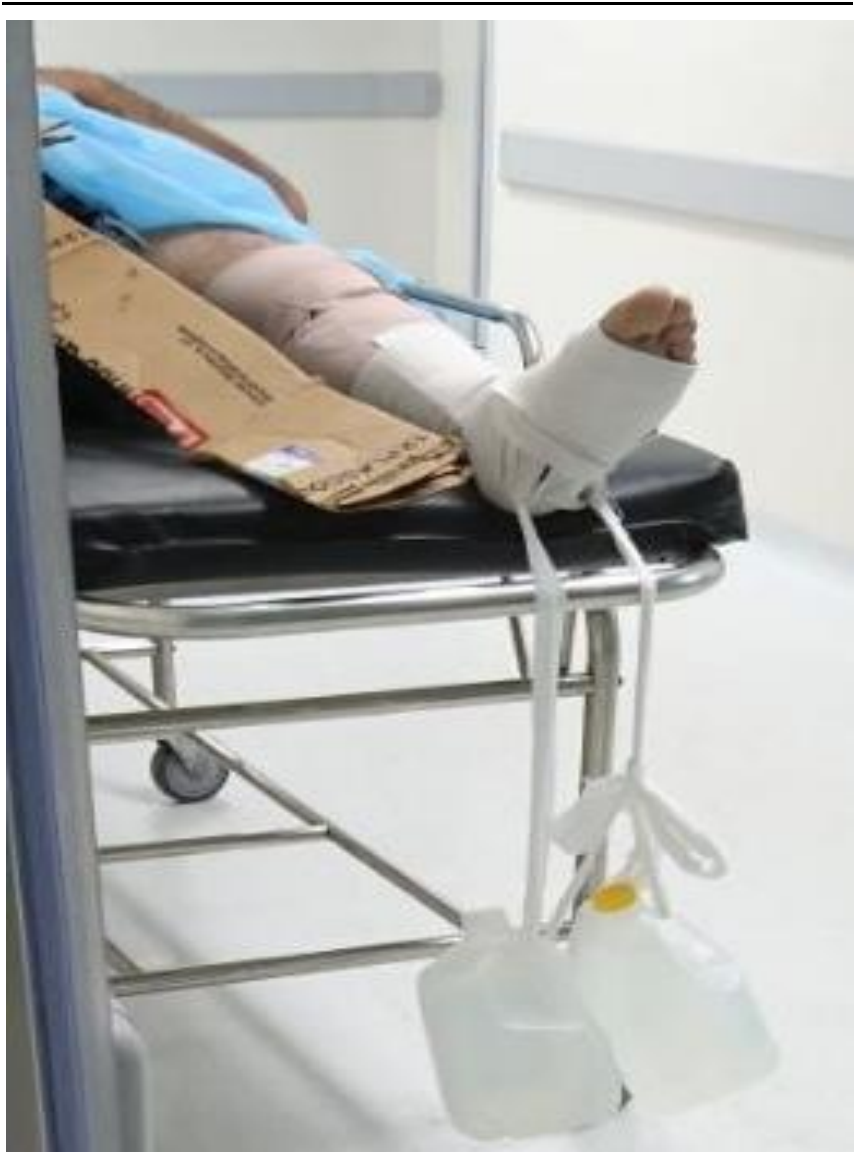

Legend: This is a patient with a lower extremity fraction [December 2017]. Note the cardboard box that was used as a splint. Also, note that the stretcher has no sheet and that the traction is being applied by two gallons of water tied to metal rods.

${ }^{1}$ EMT-P, MD, Pontificia Universidad Católica Madre y Maestra, Santiago, Dominican Republic.

About the Author: Reynolds A. Kairus graduated from Pontificia Universidad Católica Madre y Maestra, Santiago de los Caballeros, Dominican Republic in June 2017 as a medical doctor. He a co-author for an investigation published in The Journal of Clinical Toxicology (D01: 10.4172/2161-0495. 1000311) and has received recognition from the The City New York - Fire Department for return of spontaneous circulation on patients in cardiac arrest. He is currently working as paramedic and preparing for the USMLES. 
Community hospitals are mainly used for ambulatory care and provide initial treatment for patients who require further care at the regional referral center. In most cases the emergency rooms are staffed by general practitioners due to the fact that Emergency Medicine is still a relatively young field in DR. The lack of general medical supplies makes accommodations like sterile dressing, bed sheets and pillows hard to come by. ${ }^{3}$ The patient's relatives are usually in charge of providing both necessary medical supplies and patient comforts.

The PHS shortage of supplies has affected every medical role. 4 Attendings, residents, interns, medical students, nursing staff, patients and their relatives on a daily basis create innovative solutions (Figure 2). In the DR PHS, medical tape is used as electrical tape, empty plastic gallon containers are used as sharp bins. If post neurosurgery patients requiring drainage, a collapsed saline bottle is used as an active suction device. As a replacement for orthopedic traction splints, gallons of water tied to the metal rods are used to stabilize long bone fractures. Physicians regularly intubate patients without a stylet - now that's impressive!

In the prehospital setting we also learn how to work under very uncomfortable circumstances. If the patient is at home, unconscious and stuck behind some furniture then we move the furniture. If intubation is indicated and the patient is lying supine on the floor then we lie prone on the floor to get a better visualization of the vocal cords, and so on. The DR PHS is very similar in that sense. If the patient is poor and cannot pay for their lab tests then we try to help or cover the bill. If there is the possibility of Pseudomonas in the water supply, patients and staff bring their own bottled water. If there is no suture kit and the bleeding control must be accomplished, then they use their gloved hands with extreme caution, and so on.

I highly recommend that students have some kind of health care provider experience prior to or during medical school. Whether that experience comes from a paid job or volunteering. It provides great familiarity, practicality, and confidence. If asked to say what three words come to mind when asked about the NYC EMS system and the PHS in DR, I would say: resourceful, efficient and resilient.

\section{Figure 2. Sterile Field.}

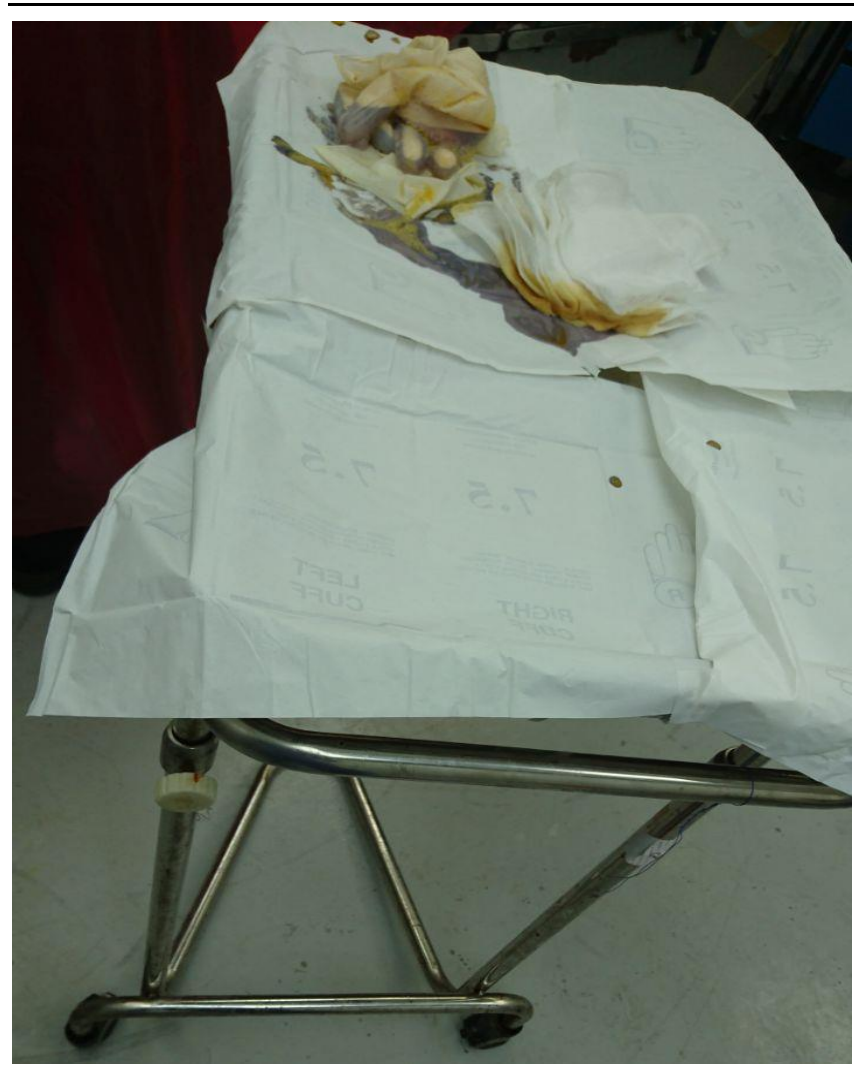

Legend: This is a picture of a sterile field used during invasive procedures [December 2017]. The inside part of a sterile glove is used as a container of Povidone-iodine and Chlorhexidine mixture. The sterile mixture is sitting on top the of 7.5 sterile glove wrapping papers that are used as a sterile barrier to place surgical equipment on. 


\section{References}

1. Weiss N, Ross E, Cooley C, Polk J, Velasquez C, Harper S, et al. Does Experience Matter? Paramedic Cardiac Resuscitation Experience Effect on Out-of-Hospital Cardiac Arrest Outcomes. Prehosp Emerg Care. 2018 May-Jun;22(3):332-337. Epub 2017 Dec 22. 2. EMT-PARAMEDIC National Standard Curriculum. (2018). National Highway Traffic Administration: United States Department of Transportation, pp.1-962.
3. Anon, (2007). [online] Available at: https://hhidr.org/wpcontent/uploads/2011/10/USAID-Health-System-Profile-DR-2007.pdf [Accessed 12 Jun. 2018].

4. Anon, (2018). [online] Available at: http://apps.who.int/medicinedocs/en/d//s21040en/ [Accessed 12 Jun. 2018].

\section{Acknowledgments}

I would like to thank doctors Cynthia Santos, Adolfo Alvino, Lynn Holden, Jose Romero and Jeremy Moriarty. Last but not least, Elizabeth Morales. I am what I am today and I will be who I will be tomorrow thanks to the guidance you all have offered. Thank you!

Conflict of Interest Statement at Funding

The Authors have no funding, financial relationships or conflicts of interest to disclose.

Author Contributions

Conception and design the work/idea, Collect data/obtaining results, Analysis and interpretation of data, Write the manuscript, Critical revision of the manuscript, Approval of the final version: RAK.

Cite as:

Kairus RA. The Experience of Transitioning from Being a New York City Paramedic to Medical Intern in the Dominican Republic. Int J Med Students. 2018 May-Aug;6(2):75-77.

This work is licensed under a Creative Commons Attribution 4.0 International License 